\title{
Middle managers, their organization and knowledge sharing: Examination of knowledge sharing maturity
}

\author{
Dr. habil. Lajos Szabó, Dr. Anikó Csepregi \\ University of Pannonia, Department of Management, H-8200, Veszprém,Egyetem utca 10, Hungary \\ szabola@gtk.uni-pannon.hu \\ University of Pannonia, Department of Management, H-8200, Veszprém,Egyetem utca 10, Hungary \\ csepregia@gtk.uni-pannon.hu
}

\section{ABSTRACT}

The purpose of this paper is to highlight the role of middle managers in the knowledge sharing process by presenting the results of a survey aiming to reveal the elements of middle managers' knowledge sharing maturity and individual and organizational characteristics affecting them. The paper is based on quantitative research. The data were gathered through questionnaires. Based on 400 usable survey responses, the authors applied principal component analysis, decision tree, analysis of variance, and post-hoc test to reveal the elements of middle managers' knowledge sharing maturity and the differences individual and organizational characteristics result in them. The study results indicate that middle managers' knowledge sharing maturity is measured with four elements and based on individual and organizational characteristics there are differences in certain elements. The originality of the paper is that past research did not investigate middle managers or their knowledge sharing maturity, only focused on the organizational level of knowledge management maturity. The effect of individual and organizational characteristics on knowledge sharing maturity has not been investigated either. This paper focuses on these aspects. The results of the survey could help not only middle managers, but top managers and other employees as well in learning how to foster knowledge sharing.

\section{Indexing terms/Keywords}

knowledge sharing, maturity, middle manager, individual, organization

\section{Academic Discipline And Sub-Disciplines}

Management, Knowledge management

\section{SUBJECT CLASSIFICATION}

Knowledge sharing Classification

\section{TYPE (METHOD/APPROACH)}

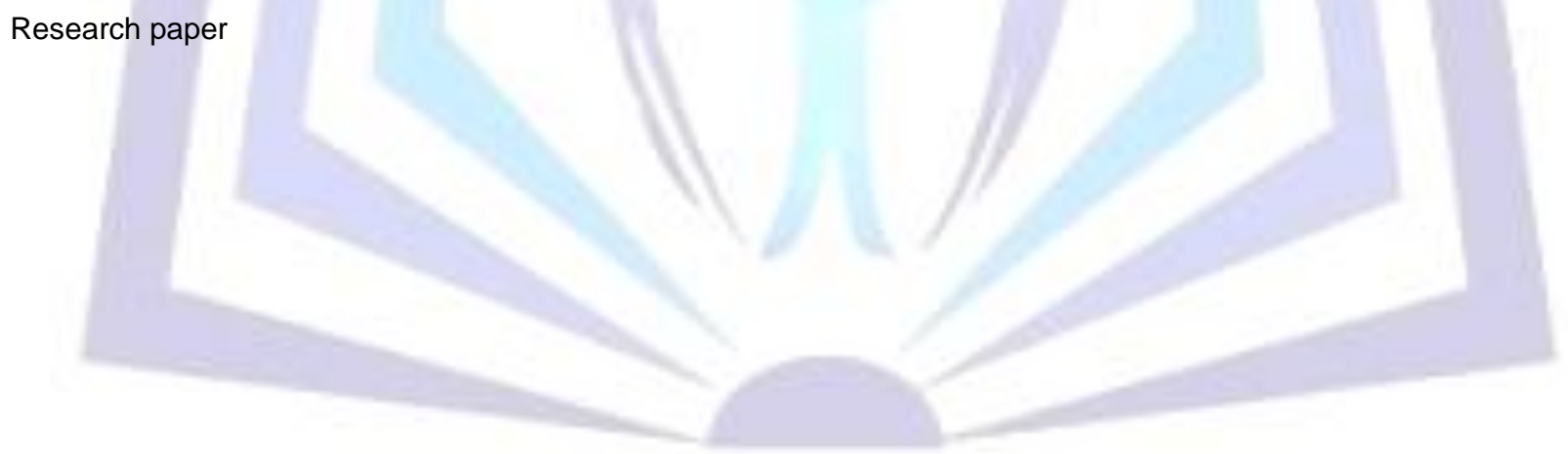

\section{Council for Innovative Research}

\section{Peer Review Research Publishing System}

Journal: Journal of Social Sciences Research

Vol .7, No.1

jssreditor.cir@gmail.com

www.jssronline.com 


\section{INTRODUCTION}

In the 1970s Chandler (1977) emphasised that middle managers' jobs cover exclusively the supervision of lower hierarchical levels, nowadays a large body of literature discusses their role from other aspects as well (Uyterhoeven, 1989; Sayles, 1993; Eaves, 2014). Middle managers have to fulfil two major integrating tasks: the integration of top management and workforce, and their own integration across functional lines (Schlesinger and Oshry, 1984). Balancing the demands and interests of these organisational members and short- and long-term business demands (Schlesinger and Oshry, 1984) are also their tasks, besides becoming adept at the integration of "hard" technical skills and "soft" skills (Barnes et al., 2001). They need to possess inter-personal skills as well, since they have to work closely with others within and also outside the organisation (Sayles, 1993). During work knowledge is required and shared. Knowledge sharing often used as keyword in journals (Walter and Ribiere, 2013) and representing the key knowledge management process in organisations is fundamental for generating new ideas and developing new business opportunities (Lin, 2007a). Forming behavior and helping the development of personal relationships with others is considered one of the most remarkable tasks of knowledge sharing (Wang and Noe, 2010; Obermayer-Kovács and Komlósi, 2014). Finally, the significance of knowledge sharing is emphasised by Dunford (2000, p.296) as follows: "much of the key knowledge is held by individuals unless there is some structure to retain it within the organisational memory".

In the first section of the paper, middle managers and their previous study directions are presented. Then knowledge management maturity focusing on the organizational level is explained. This is followed by knowledge sharingand its influencing factors. The second section presents the research framework, while the third introduces the methodology. The results of the study can be found in the fourth section, the discussion and conclusion in the fifth. The paper ends with the practical implications and the future research plans.

\section{Middle managers}

In the last 30 years there has been no universally accepted definition of middle managers (Csepregi, 2012a). Uyterhoeven (1989, p.136) states that a middle manager is someone "who is responsible for a particular business unit at the intermediate level of the corporate hierarchy". Ireland (1992, p.18) describes them as employees working between an organisation's top-level and first-level managers, and their jobs contain the integration of "the intentions of top-leve managers with the day-to-day operational realities experienced by first-level managers". Regarding their organizational position Staehle and Schirmer (1992, p. 70) emphasise that middle managers are "employees who have at least two hierarchical levels under them and all staff employees with responsibility for managing personnel". Besides the number of levels below them, the possession of functional speciality is also highlighted concerning their determination (Conway and Monks, 2011).

Previous studies investigating middle managers can be divided into two categories (Csepregi, 2012a). One of them examined the middle manager - top manager relationship (Dutton et al., 1997; Nonaka, 1988; Pappas et al., 2003; Mantere, 2008) while the others dealt with the middle manager - subordinate relationship (Crouch and Yetton, 1998; Xin and Pelled, 2003; Glasø and Einarsen, 2006). However, Kaplan (1984, p.38) pointed out that middle managers' vertical relationships also extend to the superior's superior and the subordinates' subordinates. Moreover, middle managers are engaged in horizontal/lateral relationships with peers, other middle managers' superiors and subordinates, as well as professionals in other organisations, not only in vertical relationships (Kaplan, 1994). Such multidirectional relationships were also identified by Uyterhoeven $(1989$, p.137): "the middle manager wears three hats in fulfilling the general management role", as a subordinate, as a superior, and as an equal, having to manage relationships upwards, downwards, and laterally.

Thus middle managers can also be determined as employees working below the top management (CEO and/or top managers) and being responsible for and working with employees hierarchically lower than themselves. They play a significant role in vertical and horizontal organisational communication and influence the management of knowledge at medium- and large-size enterprises as well (Csepregi, 2012b).

\section{Knowledge management maturity models}

An entity's development is represented by maturity models (Klimko, 2001). The existing knowledge management maturity models can be categorized into two groups, depending on whether they are based on the Software Engineering Institute's (SEI) Capability Maturity Model (CMM) or not. An example of 'CMM-based' knowledge management maturity models is Paulzen et al. (2002) Knowledge Process Quality Model. The levels are usually named after the corresponding levels of CMM. 'Non-CMM-based' knowledge management maturity models contain examples of KPMG's (2000) Knowledge Journey, or Klimko's (2001) KMMM. These models differ in the number of levels from CMM-based knowledge management maturity models. The other two types of maturity models are the 'staged' and the 'continuous' maturity models. In 'staged' maturity models a single entity's development is described by a limited number of maturity levels characterised by certain requirements and have to be achieved in a strict order (Paulk et al., 1994). 'Continuous' maturity models maturity is interpreted in the context of processes and organisations can simultaneously develop in different 'process areas' (Klimko, 2001). An example of the continuous maturity model is the 'Knowledge Management Profile' maturity (Gaál et al., 2011) that has revealed the importance of knowledge sharing as well. 


\section{Knowledge sharing and influencing factors}

Moeller and Svahn $(2004$, p.220) stress that knowledge sharing is "sharing not only codified information"..."but also management beliefs, images, experiences, and contextualized practices". While, Li (2010, p.40) defines knowledge sharing as an activity, but one in which "participants are involved in the joint process of contributing, negotiating and utilizing knowledge". From another viewpoint, knowledge sharing is described as a choice being used and selected differently by different individuals (Bhatt, 2002). According to Mueller (2012, p.436) at least two people, groups, or organizations are involved in knowledge sharing "the sender, who is willing and able to share knowledge, and the receiver, who is willing and able to combine this new knowledge with his or her existing knowledge and use it". We define Kknowledge sharing as a two-way process between the knowledge giver(s) and receiver(s), as parties, who exchange their knowledge found in their minds or the knowledge found in electronic or traditional documents. In our viewpoint knowledge sharingcan also be simultaneous (parties involved are all present), or consecutive (parties make their knowledge explicit). Christensen's (2007, p.37) states that the goal of knowledge sharing "can either be to create new knowledge by differently combining existing knowledge or to become better at exploiting existing knowledge". Storing public knowledge, compared to private knowledge, can result in knowledge sharing (Magnier-Watanabe and Senno, 2010), whilst the value of costs and benefits of knowledge sharing is valued differently, since it depends on the goal orientation forming the knowledge types being share and the partners to it is shared with (Swift et al., 2010).

Since knowledge sharing requires the willingness to cooperate (Assudani, 2005; Zboralski, 2009), several studies have been published measuring individual knowledge sharing from the point of view of employee's willingness and intention towards knowledge sharing or investigated self-reported knowledge sharing behaviours (Reychav and Weisberg, 2010; Suppiah and Sandhu, 2011). Willingness can be characterised by "the extent to which an individual is prepared to grant other group members access to his or her individual intellectual capital” (de Vries et al. 2006, p.117). Willingness can also appear when conceptualizing knowledge sharing: at the source's willingness to share knowledge and the receiver's willingness to acquire the source's knowledge (Gupta, Govindarajan, 2000). The reciprocal feature of knowledge sharing, when one gets something valuable in return, is also connected to willingness (Vuori and Okkonen, 2012). This appears more dominantly among new employees, who in order to gain knowledge are more willing to share theirs with others (McAdam et al., 2012). Finally, the willingness to share knowledge can result in a more effective knowledge resource management of organizations (Amayah, 2013). Knowledge sharing intention is "one's expectation of exchanging information, skills, or expertise with others, and where such sharing will benefit the sharer's organization" (Witherspoon et al., 2013, p.252). The different intentions of knowledge sharingcan also influence with whom the knowledge is shared (Wang and Noe, 2010). Studies have shown that those are more likely to express their intentions to knowledge sharing who are confident in their ability to share useful knowledge (Cabrera et al., 2006; Lin, 2007a). Finally, according to Brachos et al. (2007) the perceived usefulness of knowledge depends on the extent to which the knowledge is perceived as meaningful, accurate, valid and innovative.

In earlier studies investigating knowledge sharingfocused on the influence of the organisation (Seba et al., 2012; Yang and Maxwell, 2012; Amayah, 2013) and thus the organisational perspective was dominant and measured. While other studies were conducted from the behavioural perspective (Matzler et al., 2008; Chow and Chan, 2008, Holste and Fields, 2010) and in this case knowledge sharing was influenced by individual behaviour.

\section{RESEARCH FRAMEWORK}

Recognising middle managers' multidirectional relationships (Uyterhoeven, 1989), and reviewing the interviews made with them that revealed the significance of their knowledge sharing practice, our study into middle managers' knowledge sharing examined both their vertical and horizontal relationships, within and between different organisational units. Our study did not investigate the leadership function, where only the middle manager-subordinate relationships would have been examined. Instead, it focused on the knowledge sharing function and its maturity.

The purpose of our study was to reveal the elements describing middle managers' knowledge sharing maturity and the components of middle managers' individual and organizational characteristics resulting in differences in these elements.

Focusing on middle managers our study aimed to answer the following research questions:

Q1: With what elements can the knowledge sharing maturity of middle managers working at medium-and large-sized enterprises be described?

Q2: How do individual and organizational characteristics influence the knowledge sharing maturity of middle managers working at medium-and large-sized enterprises?

Knowledge sharing maturity refers to middle managers' (not organizations') knowledge sharing development level and is defined by two dimensions ('availability' and 'usefulness of knowledge') and two directions (middle manager-middle manager and middle manager-subordinate) (Csepregi, 2012b). 'Availability' is the extent to which the middle managers, their subordinates, and other middle managers are willing to spend time helping one another by sharing their knowledge. 'Usefulness of knowledge' refers to whether the middle managers, their subordinates, and other middle managers possess the knowledge useful for others (Csepregi, 2012b). Considering these dimensions and directions, the values showing the development level of the knowledge sharing maturity elements can be revealed. Based on these values however the study aimed neither to create a complex index nor to differentiate among knowledge sharing maturity levels. Instead, it aimed to reveal individual and organizational characteristics resulting in differences within the elements creating (at least) two classes, one characterised by 'the most favourable result' (higher value=higher knowledge sharing development level) and 
the other by 'the least favourable result' (lower value=lower knowledge sharing development level). Concerning 'individual characteristics', the middle manager's age, functional area, and the length of working years at the organization are examined. 'Organizational characteristics' focus on the type of, the activity of, and the customer claims fulfilled by the middle manager's organization (Csepregi, 2012a). Although, previous studies gathered information of these categories, they did not investigate them further (Amayah, 2013; Suppiah and Sandhu, 2011). In this paper we focus on these, often neglected, individual and organizational characteristics and knowledge sharing maturity (Fig 1).

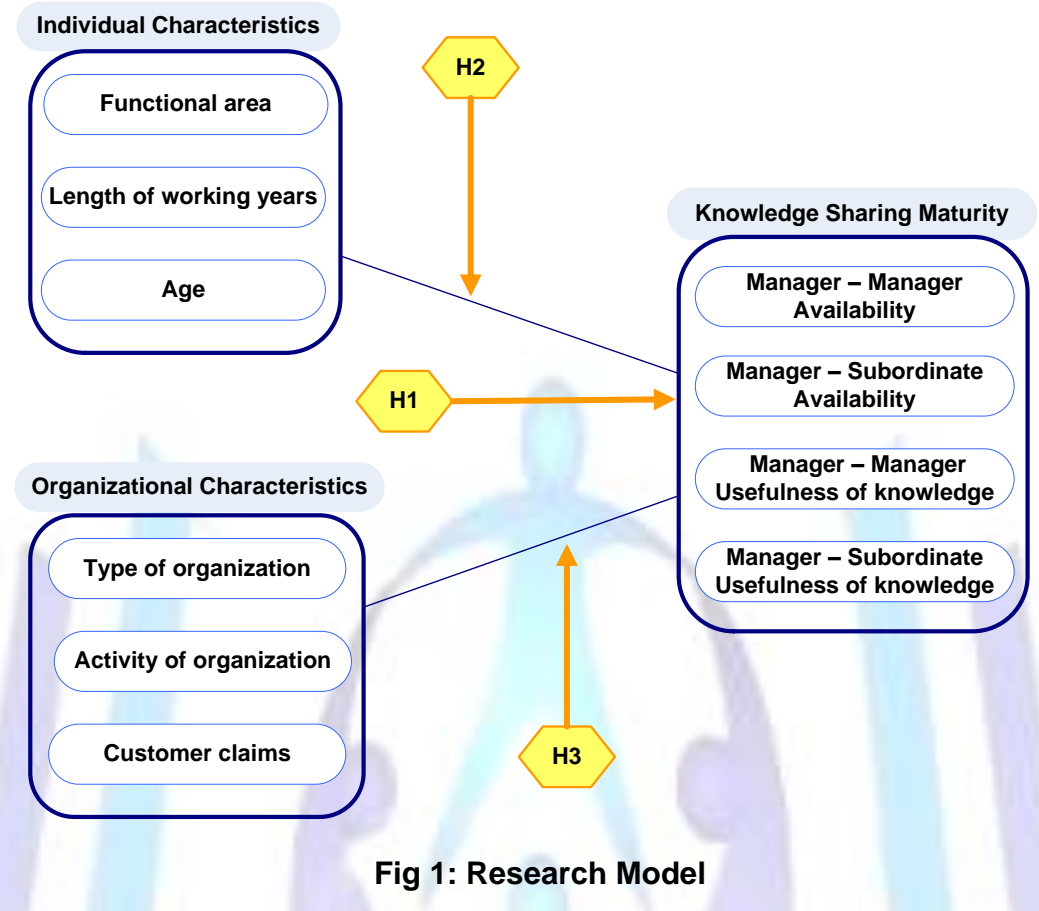

Three hypotheses were stated concerning the study.

$\mathrm{H} 1$ : The knowledge sharingmaturity element of middle managers working at medium- and large-sized enterprises can be revealed by the two dimensions and directions.

$\mathrm{H}$ 2: There can be differences in the knowledge sharingmaturity elements of middle managers working at medium- and large-sized enterprises on the basis of individual characteristics.

H3: There can be differences in the knowledge sharing maturity elements of middle managers working at medium- and large-sized enterprises on the basis of organizational characteristics.

\section{RESEARCH METHODOLOGY}

\section{Data collection}

Having no database containing the number of middle managers it was difficult to identify their total number in Hungary. Thus we had to look into the registered number of medium- and large-sized enterprises in the statistics of the Hungarian Central Statistical Office (KSH). Based on these data, it was possible to determine the registered number of middle- and large-sized enterprises in Hungary. It was 5,545 in 2007, and the average number of these enterprises between 2007 and 2010 was 5,780 ( $\mathrm{KSH}, 2010)$. This is the theoretical population of the study. 4,000 enterprises covering a wide range of economic sectors were selected randomly for the study, and cover letters and questionnaires were sent by post or electronically, with the request to be filled in by at least one middle manager (Csepregi, 2012a; Csepregi, 2012b).

\section{Measures}

The questionnaire regarding knowledge sharing maturity contained questions about the extent of 'availability' and 'usefulness of knowledge' based on a five point Likert scale. Availability was measured from the following standpoints: the middle managers' availability for other middle managers when the middle managers in our sample are asked for help, other middle managers' availability for the middle managers when they ask for help; and the same regarding the middle manager-subordinate availability. On the other hand, the usefulness of knowledge is measured from the following standpoints: the usefulness of the knowledge supplied by the middle managers to other middle managers, the usefulness of the knowledge shared by other middle managers to the middle managers in our sample; and the same regarding the middle manager-subordinate usefulness of knowledge (Csepregi, 2012a). 
The questionnaire also asked information concerning the middle managers' 'individual characteristics', such as their age, length of working years at their organisation (determining being newcomers or old-timers) and the functional area where they work, and regarding the characteristics of their organizations such as the type of, the activity of, and the customer claims fulfilled by their organization. The type of the middle manager's organization aimed to reveal the ownership of their organization considering the combination of the followings: national or foreign owned, privately or state owned. The activity of their organization aims to focus on the dominating organizational activity: service or production. The customer claims fulfilled by the organization refers to the demands of customers based on a five point Likert scale in which the two extremes are not changing and fix customer claims, and often changing and complex customer claims (Csepregi, 2012a).

\section{RESULTS}

\section{Descriptive statistics}

Between 2007 and 2010, 400 completed questionnaires, being the final sample of the study, were returned from middle managers in manufacturing/production(12\%), maintenance(13\%), logistics(8\%), finance/accountancy/controlling(10\%), quality management(4\%), human resources(14\%), project management(8\%), commerce/purchase/sale/marketing(17\%), and research and development(14\%). The organisations they represented were in commerce, building trade, processing, logistics/warehousing, mining, telecommunications, agriculture, tourism/catering, education, government, healthcare/ social support, estate agency, financial intercession, information technology, electricity/gas/fume/water supply, and other economic sectors, having a variety of ownership ranging from being fully national and private owned(36\%), fully national and state owned(14\%), with a national majority and privately owned(9\%), with national maturity and state owned(8\%), with foreign majority $(7 \%)$ and fully foreign( $26 \%)$. These organizations were involved either only in production activity $(28 \%)$, or mainly in production activity(33\%), or mainly in service activity(18\%), or only in service activity(21\%) (Csepregi, 2012a).

\section{Hypotheses testing}

Concerning hypothesis 1 we chose principal component analysis (PCA) to describe knowledge sharing maturity by certain number of elements and to retain as much of the information (variation) of the original variables as possible. As a result of PCA the number of principal components is also less then the number of variables, since this method reduces the number of variables (Myatt, Johnson, 2009). To determine the appropriateness of the data set for PCA Kaiser-Meyer-Olkin (KMO) measure of sampling adequacy and Bartlett's test of sphericity were used. The KMO test with the value of 0.740 was above the accepted limit of 0.5 , which is held as a critical value. The Bartlett test yields a high Chi-square value of 1105.361 , and a significance level of 0.000 which was under the accepted limit of 0.05 . Thus both tests verified that the data were appropriate for PCA. The percentage of the cumulative eigenvalues in the Total Variance Explained table rose up to $80.614 \%$ when taking into account four components (\% of Variance: Component_1: 21.085; Component_2: 20.395; Component_3: 19.943, Component_4: 19.190), which thus fulfilled the aim of our initial assumption regarding the number of elements (Csepregi, 2012a; Gaál et al., 2012a). Regarding rotation varimax rotation method was chosen. Table 1. presents the four principal components with the belonging variables and their principal component loadings after rotation (Csepregi, 2012a).

Table 1. Knowledge sharing maturity elements

\begin{tabular}{|c|c|c|}
\hline $\begin{array}{l}\text { Knowledge sharing maturity } \\
\text { elements (components) }\end{array}$ & Variables & $\begin{array}{l}\text { Component } \\
\text { loadings }\end{array}$ \\
\hline \multirow{2}{*}{$\begin{array}{l}\text { Middle manager - middle manager } \\
\text { availability }\end{array}$} & Availability of other middle managersto middle managers & .858 \\
\hline & Availability of middle managersto other middle managers & .833 \\
\hline \multirow{2}{*}{$\begin{array}{l}\text { Middle manager - subordinate } \\
\text { availability }\end{array}$} & Availability of subordinates to middle managers & .858 \\
\hline & Availability of middle managersto subordinates & .854 \\
\hline \multirow{2}{*}{$\begin{array}{l}\text { Middle manager - middle manager } \\
\text { usefulness of knowledge }\end{array}$} & Usefulness of other middle managers' knowledge to middle managers & .899 \\
\hline & Usefulness of middle managers' knowledge to other middle managers & .823 \\
\hline \multirow{2}{*}{$\begin{array}{l}\text { Middle manager - subordinate } \\
\text { usefulness of knowledge }\end{array}$} & Usefulness of subordinates' knowledge to middle managers & .756 \\
\hline & Usefulness of middle managers' knowledge to subordinates & .874 \\
\hline
\end{tabular}

Regarding hypothesis 2 and hypothesis 3 to reveal the differences in the knowledge sharing maturity elements concerning the influencing factors decision tree, as the first method, was chosen. With individual and organizational characteristics as influencing factors, it was possible to determine the elements being the stronger classifiers and to reveal classes within these elements (influencing factors). After separating the classes, their group means were compared in pairs with analysis of variance. This was followed by separating the classes with 'the most favourable results' within each element of influencing factors from the classes with 'the least favourable results' (Table 2.). Based on these, the most and the least favourable results of the classes were combined and with these combinations additional groups (the least-least favourable and the most-most favourable results) were formed (Table 3.) (Csepregi, 2012a). 
Table 2. Decision tree based class separation

\begin{tabular}{|c|c|c|c|c|c|c|c|c|c|c|c|c|}
\hline \multirow{3}{*}{$\begin{array}{c}\text { KS maturity } \\
\text { elements }\end{array}$} & \multicolumn{6}{|c|}{ Individual characteristics } & \multicolumn{6}{|c|}{ Organizational characteristics } \\
\hline & \multicolumn{2}{|c|}{ functional area } & \multicolumn{2}{|c|}{$\begin{array}{c}\text { length of } \\
\text { working years }\end{array}$} & \multicolumn{2}{|c|}{ age } & \multicolumn{2}{|c|}{\begin{tabular}{c|} 
type of \\
organization
\end{tabular}} & \multicolumn{2}{|c|}{$\begin{array}{c}\text { activity of } \\
\text { organization }\end{array}$} & \multicolumn{2}{|c|}{ customer claims } \\
\hline & $\begin{array}{c}\text { least } \\
\text { favourable }\end{array}$ & $\begin{array}{c}\text { most } \\
\text { favourable }\end{array}$ & \begin{tabular}{|c|} 
least \\
favourable
\end{tabular} & $\begin{array}{c}\text { most } \\
\text { favourable }\end{array}$ & $\begin{array}{c}\text { least } \\
\text { favourable }\end{array}$ & $\begin{array}{c}\text { most } \\
\text { favourable }\end{array}$ & \begin{tabular}{c|} 
least \\
favourable
\end{tabular} & $\begin{array}{c}\text { most } \\
\text { favourable }\end{array}$ & $\begin{array}{c}\text { least } \\
\text { favourable }\end{array}$ & $\begin{array}{c}\text { most } \\
\text { favourable }\end{array}$ & $\begin{array}{c}\text { least } \\
\text { favourable }\end{array}$ & $\begin{array}{c}\text { most } \\
\text { favourable }\end{array}$ \\
\hline \begin{tabular}{|c|} 
Middle \\
manager - \\
middle \\
manageravai \\
lability
\end{tabular} & $\begin{array}{l}\text { 'hard' } \\
\text { (1) }\end{array}$ & $\begin{array}{l}\text { 'soft' } \\
\text { (1) }\end{array}$ & $\begin{array}{c}\text { less than } \\
3 \text { years } \\
(2)\end{array}$ & $\begin{array}{c}\text { more than } \\
3 \text { years } \\
(2)\end{array}$ & 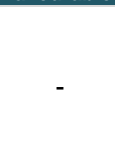 & 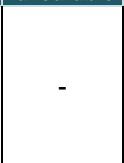 & $\begin{array}{c}\text { national, } \\
\text { state } \\
\text { owned } \\
(1)\end{array}$ & $\begin{array}{l}\text { national, } \\
\text { privately } \\
\text { owned } \\
\text { (1) }\end{array}$ & \multirow{2}{*}{$\begin{array}{l}\text { service } \\
\text { (2) }\end{array}$} & \multirow{2}{*}{$\begin{array}{c}\text { production } \\
\text { (2) }\end{array}$} & 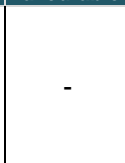 & 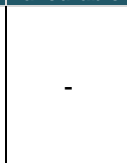 \\
\hline \begin{tabular}{|c|} 
Middle \\
manager - \\
subordinate \\
availability
\end{tabular} & $\begin{array}{l}\text { 'hard' } \\
\text { (2) }\end{array}$ & $\begin{array}{l}\text { 'soft' } \\
(2)\end{array}$ & $\begin{array}{c}\text { less than } \\
3 \text { years } \\
(1)\end{array}$ & $\begin{array}{c}\text { more than } \\
3 \text { years } \\
(1)\end{array}$ & - & - & $\begin{array}{c}\text { national, } \\
\text { privately } \\
\text { owned } \\
(1)\end{array}$ & $\begin{array}{c}\text { national, } \\
\text { state } \\
\text { owned } \\
(1)\end{array}$ & & & - & - \\
\hline \begin{tabular}{|c|} 
Middle \\
manager - \\
middle \\
manageruse \\
fulness of \\
knowledge
\end{tabular} & - & - & \multirow{2}{*}{$\begin{array}{c}\text { less than } \\
3 \text { years } \\
(1)\end{array}$} & \multirow{2}{*}{$\begin{array}{c}\text { more than } \\
3 \text { years } \\
\text { (1) }\end{array}$} & - & - & - & 年 & - & - & $\begin{array}{c}\text { not } \\
\text { changing, } \\
\text { fix } \\
(1)\end{array}$ & $\begin{array}{c}\text { often } \\
\text { changing, } \\
\text { complex } \\
(1)\end{array}$ \\
\hline \begin{tabular}{|c|} 
Middle \\
manager - \\
subordinate \\
usefulness \\
of \\
knowledge
\end{tabular} & - & - & & & $\begin{array}{c}\text { younger } \\
\text { than } 35 \\
(2)\end{array}$ & $\begin{array}{c}\text { older } \\
\text { than } 35 \\
(2)\end{array}$ & & - & - & - & - & \\
\hline (1)strongest c & & bonon & tro & classifier & & & & & & & & \\
\hline
\end{tabular}

Table 3. Combination of influencing factor elements

\begin{tabular}{|c|c|c|c|c|}
\hline \multirow{2}{*}{$\begin{array}{l}\text { KS maturity } \\
\text { elements }\end{array}$} & \multicolumn{2}{|c|}{ Individual characteristics } & \multicolumn{2}{|c|}{ Organizational characteristics } \\
\hline & $\begin{array}{l}\text { least-least } \\
\text { favourable }\end{array}$ & most-most favourable & least-least favourable & most-most favourable \\
\hline $\begin{array}{l}\text { Middle manager - } \\
\text { middle } \\
\text { manageravailability }\end{array}$ & $\begin{array}{c}\text { 'hard' } \\
\text {-less than } 3 \text { years }\end{array}$ & $\begin{array}{c}\text { 'soft' } \\
\text {-more than } 3 \text { years }\end{array}$ & $\begin{array}{l}\text { national,state owned } \\
\text {-service }\end{array}$ & $\begin{array}{c}\text { national,privately owned } \\
\text {-production }\end{array}$ \\
\hline $\begin{array}{c}\text { Middle manager - } \\
\text { subordinateavailability }\end{array}$ & $\begin{array}{c}\text { less than } 3 \text { years } \\
\text {-'hard' }\end{array}$ & $\begin{array}{c}\text { more than } 3 \text { years } \\
\text {-'soft' }\end{array}$ & $\begin{array}{c}\text { national,privately owned } \\
\text {-service }\end{array}$ & $\begin{array}{c}\text { national,state owned } \\
\text {-production } \\
\end{array}$ \\
\hline \begin{tabular}{|c|} 
Middle manager - \\
middle \\
managerusefulness of \\
knowledge
\end{tabular} & less than 3 years & more than 3years & not changing,fix & often changing,complex \\
\hline \begin{tabular}{|c|}
$\begin{array}{c}\text { Middle manager - } \\
\text { subordinateusefulness } \\
\text { of knowledge }\end{array}$ \\
\end{tabular} & $\begin{array}{l}\text { less than } 3 \text { years } \\
\text {-younger than } 35\end{array}$ & $\begin{array}{l}\text { more than } 3 \text { years } \\
\text {-older than } 35\end{array}$ & & - \\
\hline
\end{tabular}

Depending on the number of these groups, analysis of variance or post hoc test was chosen, because by comparing the groups with the least-least favourable and the most-most favourable results we aimed to reveal whether significant difference exists between them, based on the individual or organizational characteristics. During the post-hoc test to prove that the means of the groups with the most-most and the least-least favourable results actually differ first we conducted a Levene's test of homogeneity of variance. When variances were assumed to be equal (variances were homogeneous) as the result of Levene's test, we used the LSD test and when variances was not assumed to be equal (variance were not homogeneous) we applied the Tamhane test. The results of the analysis are presented in Table 4. 
Table 4. Combination of influencing factor elements

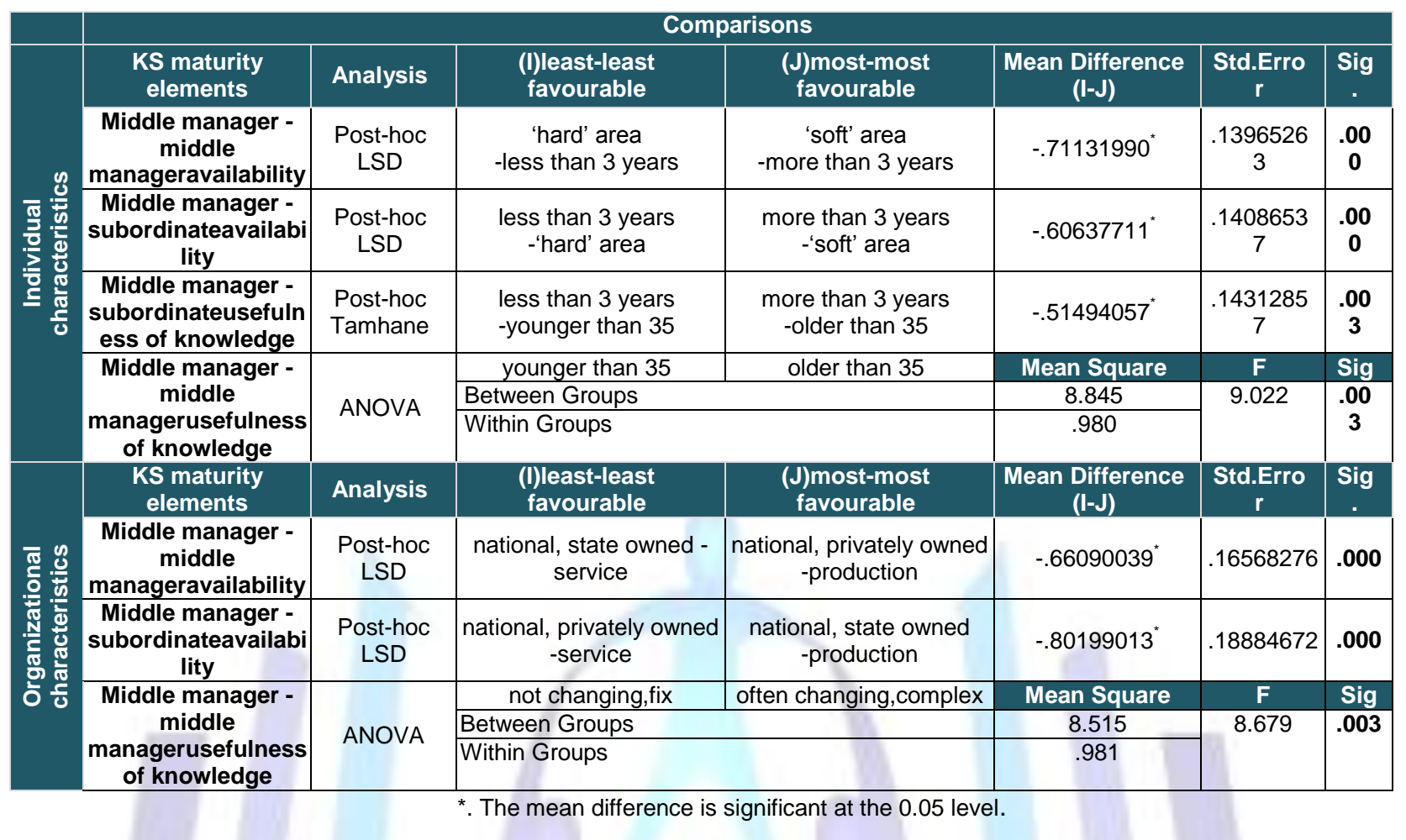

\section{DISCUSSION AND CONCLUSION}

Based on the analysis and the follow-up interviews conducted with middle managers, the following theses could be stated.

T1: The knowledge sharing maturity of middle managers working at medium- and large-sized enterprises is determined by the availability among middle managers, the availability among the middle managers and their subordinates, the usefulness of knowledge among middle managers, and the usefulness of knowledge among the middle managers and their subordinates.

The availability among middle managers is the middle manager-middle manager availability and measuring the value of their availability. While the availability among the middle managers and their subordinates stands for the middle managersubordinate availability. Here also the value of their availability was revealed. The usefulness of knowledge among middle managers focuses on the middle manager-middle manager usefulness of knowledge and determines the value of the usefulness of knowledge to each other. The usefulness of knowledge among the middle managers and their subordinates is the middle manager-subordinate usefulness of knowledge and reveals the value of the usefulness of knowledge to each other. The higher the values are, the higher the knowledge sharing maturity is (Csepregi, 2012a).

The remaining theses are also considered valid for middle manager working at medium- and large-sized enterprises.

T2.1: There are differences in the availability among middle managers primarily by the middle managers' functional area and secondly by the length of their working years.

This means that middle managers primarily working in 'soft' functional areas as in the areas of HR, R\&D, project management, commerce, purchasing, sales, and marketing and secondly have worked there for more than three years are more available for other middle managers and vice versa. The explanation is twofold. First, because middle managers working in 'soft' functional areas are characterised by high levels of interaction, furthermore other middle managers need to keep up-to-date with what goes on in their organisations. Relationship orientation in these areas and having good relationships with others is dominant and significant. Second, middle managers acquire knowledge during the length of their working years. The longer this is the easier it is to understand one another, their organisations, and its goals. These old-timers help the work of others by being available. Their role should be promoted to achieve the motivation of old-timer - newcomer knowledge sharing (Hermanrud, 2012). Thus teamwork, the ability to work as part of a team, and sharing knowledge are of high importance (Rosendaal, 2009). Successful team performance and its connection to trust have been widely studied, and trust has also been declared to be a key feature of successful and effective teams (Berry, 2011; Politis, 2003).

While middle managers primarily working in 'hard' functional areas as in the areas of manufacturing, production, maintenance, logistics, quality management, finance, accountancy, and controlling and secondly have worked there for less than three years, thus being newcomers, are less available for other middle managers and vice versa. It is challenging to encourage knowledge sharing across organizational units since employees have limited interaction with 
other units and managers (Mehra et al., 2006). The explanation is twofold. The first explanation lies with the low interactive nature of 'hard' functional areas. Employees perceiving a work environment representing practices, procedures, or behaviours like this will presume this behaviour is expected (Pullig et al., 2002). Relying on rules and regulations, being task oriented, and the domination of individual work and responsibility also require people who like control, rules, individual work and responsibility. Thus, middle managers working in these areas may seem less open, and less available compared to those working in 'soft' functional areas (Csepregi, 2012b). In 'hard' functional areas the knowledge outflows can represent the loss of the area's knowledge, as a results uncertainty concerning knowledge sharing may occur, whether it is viewed as welcomed by others or not (Boh and Wong, 2013). The second explanation stems from the length of working years, thus being newcomers. The interest in knowledge sharing can differ between newcomers and old-timers (Østerlund and Carlile, 2005). Thus newcomers may be viewed by other middle managers as having different interest in knowledge sharing, besides being unaware of the organizational goals or communication practices and lacking in adequate experience (Csepregi, 2012b). This is understandable, but can be misleading. Newcomers are willing to share their knowledge in exchange for gaining the knowledge they should have (McAdam et al., 2012). Moreover, employee's personal characteristics and their purpose can also have an effect on the extent of knowledge sharing, e.g. newcomers trying to impress colleagues may use techniques that others do not (Wang and Noe, 2010).

T2.2: There are differences in the availability among the middle managers and their subordinates primarily by the middle managers' length of working years and secondly by their functional area.

Meaning that middle managers who primarily have worked at their organizations for more than three years and secondly work in 'soft' functional areas are more available for their subordinates and vice versa (Gaál et al., 2012b). The length of working years in their organisations results in reciprocal middle manager-subordinate trust based on familiarity with one another, their common workplace, and their collaboration during their work (Csepregi, 2012b). Trusting and collaborating also lead to greater willingness to share knowledge and expertise (Delong and Fahey, 2000). A previous studies have examined the relationship between trust and the willingness to share knowledge and also knowledge sharing behaviour (Hinds and Pfeffer, 2003; Renzl, 2008; Ho et al., 2010). Furthermore, the support of managers for knowledge sharing has been shown to be positively related to the willingness to help others and to share knowledge with them (Connelly and Kelloway, 2003; Lin, 2007b). The experience and knowledge gained in these areas and the middle managers support provided during these working years result in enhanced subordinate acceptance and respect and influence subordinates to be willing to share their knowledge. The extent of subordinates willing to share knowledge is also influenced by the support received during the years (Tan and Zhao, 2003). So in the highly interactive nature and cooperative climate of 'soft' functional areas middle managers are found more available, more willing to share knowledge. In a ward and cooperative climate knowledge providers (as middle managers) seem more accessible and willing to share their expertise, knowledge (Alavi et al., 2005).

Furthermore, middle managers primarily being newcomers, have worked at their organizations for less than three years and secondly work in 'hard' functional areas are less available for their subordinates and vice versa (Gaál et al., 2012b). Trust based on middle manager-subordinate familiarity does not have time to develop since middle managers do not have time to familiarise themselves with their organisations and/or functional areas. The lack of time thus inhibits knowledge sharing as well (Davenport and Prusak, 1998). Moreover, the lack of trust can lead to competitive confusion concerning the other being an ally or a competitor (Powell et al., 1996). Consequently, the middle manager-subordinate availability is lower than they would have been otherwise. In addition, the rules, the routines, the quantitative targets and their realisation dominate 'hard' functional areas more than 'soft' functional areas. Having these does not mean that open knowledge sharing can appear or be fostered, but creating a warm and cooperative climate can facilitate the willingness to share (Boh and Wong, 2013). On the other hand, the rules, target and their realization are considered generally accepted and known by subordinates, which is not always the case. Thus, middle managers may fail to perceive the need to be available for their subordinates, and can be less available than they could be otherwise. By default, subordinates can also be less available for their middle managers because they have to find solutions to problems without their middle managers' collaboration. During this problem solving process they interact with tasks and gain, create new (tacit) knowledge measured by knowledge application and acquisition (Novick and Bassok, 2005; Buehner et al., 2008, Shariq and Vendelo, 2008).

T2.3: There are differences in the usefulness of knowledge among middle managers by the middle managers' length of working years.

The results show that the knowledge of middle managers, who have worked at the organization for more than three years, is more useful for other middle managers and vice versa. Thus the length of working years in their organization mattered. Being old-timers and thus having the knowledge and the understanding of the organisation has significance alongside earning the trust of other middle managers (Csepregi, 2012a). The credibility and the likability of a person have a great effect on the usefulness of knowledge (Sussman and Siegal, 2003). Considering the usefulness of someone's knowledge it is also a judgement made in a particular context (Menon and Varadarajan, 1992). In the case of middle managers the usefulness is judged based on the length of working years.

Whilst the knowledge of middle managers, who have worked at the organization for less than three years being newcomer, is considered less useful for other middle managers and vice versa. These newcomers still lack the experience regarding the organizational communication practice that could assist their knowledge sharing(Csepregi, 2012a). They also enter the organization with a social identity influencing their view of other social identities and also their learning process (Hermanrud, 2012). Interview with middle managers revealed that other middle managers thus behave reservedly with them, do not trust them until they get to know them and their work better. It takes time to earn trust and find others 
knowledge useful. Since unjustified trust can result in the misuse or even the misapplication of knowledge (Sondergaard et al., 2007, Wang and Noe, 2010). Other middle managers may not consider the newcomers' knowledge useful enough during the first few working years. Perceiving one's knowledge useful is related to the degree to which one believes that a mechanism could result in the enhancement of one's performance. (Boh and Wong, 2013). However, if other middle managers believe that newcomers do not have the knowledge they need to enhance their performance, they will not find their knowledge useful. Adopting or forcing the experience or successful practices learned at previous organizations may also lead to resistance when the culture, practice of their organization significantly differs from the previous ones. Organizational culture and its importance and effect on employees' knowledge sharing has been widely studied (Alavi et al., 2005; Balogh et al., 2011; Bogdány and Costa, 2013; Bognár, 2014; Pasher and Ronen, 2011; Suppiah and Sandhu, 2011; Lambe, 2014) One of the three stages of acculturation is adaptation which is considered to be negative if someone feels mistreated and shown resistance (Nahavandi and Malekzadeh, 1993). However by integration, being a mode of acculturation, psychological adaptation could be achieved easier and acculturative stress could be lower and thus more favourable inter-group relations could be achieved (Berry et al., 1987; Nahavandi and Malekzadeh, 1988).

T2.4: There are differences in the usefulness of knowledge among the middle managers and their subordinates primarily by the middle managers' length of working years and secondly by their age.

This means that the knowledge of middle managers, who primarily have worked at the organization for more than three years and secondly are older than 35, is considered more useful for their subordinates and vice versa. The length of working years results in enhanced experience and knowledge of their organisation and their particular functional area. This leads to subordinates' acceptance and/or respect towards old-timers. Age, if combined with length of working years, also leads to enhanced acceptance and/or respect (Csepregi, 2012b). Prior to this study, other Hungarian researchers (Bakacsi et al., 2002; Heidrich and Alt, 2009) had reached similar conclusions studying the Hungarian propensity for high power distance and paternalistic leadership style. Therefore, higher regard for older rather than younger middle managers is accepted in Hungary.

In contrast, the knowledge of middle managers, who primarily have worked at the organization for less than three years, thus being newcomers, and secondly are younger than 35, is less useful for their subordinates and vice versa. These newcomers have insufficient experience of their functional areas and of coordinating and communicating with their subordinates (Csepregi, 2012b). Acceptance for middle managers less than 35 years old in Hungary is harder. No matter how useful the knowledge might be, it only becomes useful for others with time that helps middle managers to become older, thus more respected, to develop adequate relationships with others. Interviews with middle managers revealed that knowledge shared by younger newcomers is usually problem-specific and of short-term relevance. Furthermore, these younger newcomers may force their expertise / knowledge acquired through education and experience gained earlier in their careers onto their subordinates and meet with resistance, particularly if there is a clash of organisational cultures. These organizational culture clashes can also occur during the merger or acquisition of organizations (Heidrich and Chandler, 2011).

T3.1: There are differences in the availability among middle managers primarily by the type and secondly by the activity of their organization.

The results show that middle managers primarily working at national and privately owned organizations and secondly working at organizations producing mostly and only physical products are more available for other middle managers and vice versa. First, privately owned organization are more flexible and less characterized by bureaucracy, however the rules and regulations in medium- and large-sized organizations are also necessary. The interviews with middle managers showed that competitions occurring with other organizations inspire middle managers to help each other, to be available within the organization. Thus the organizational goals are achieved and competition with organizations is more successful. In organizations mainly dealing with production activity, before buying resources/ selling products middle managers have to find time to discuss the significant conditions with other middle managers (Csepregi, 2012a). Since successful production and selling is the common goal of manager, having a good relationship and co-operating with others and members of the supply chain is of high importance. However supply chain members being in competition may cause the need to maximize their self-interest having its effect on knowledge sharing willingness (Cheng et al., 2008).

While, middle managers primarily working at national and state owned organizations and secondly working at organizations providing mostly and only services are less available for other middle managers and vice versa. Bureaucracy being a general feature of state owned organizations, here in some cases unnecessary rules and regulations result in routine and exhausting paper work. In order to manage and control knowledge one of the many forms of bureaucracy is the commoditization of knowledge (Brivot, 2011). In these organizations by having no external competition, middle managers are neither fostered to work together with other middle managers, nor do they feel the need to help others. The different functional areas are also separate, relationship barely exists between middle managers and their cooperation is nearly unremarkable (Csepregi, 2012a). Interviews with middle managers showed that not every middle manager feels the need to help others in case of problems related to services provided to customers, thinking those who cause it will/have to solve it. This shows that during service activities the individual features dominate, resulting in less available and cooperative middle managers (Csepregi, 2012a). Concerning training and cooperation, information asymmetry and the lack of willingness can also appear from middle managers (Ekpo et al., 2014).

T3.2: There are differences in the availability among the middle managers and their subordinates primarily by the type and secondly by the activity of their organization. 
This means that middle managers primarily working at national and state owned organizations and secondly working at organizations producing mostly and only physical products are more available for their subordinates and vice versa (Gaál etl al, 2013). Within state owned organizations because there is no fear of fierce competition thus middle managers and their subordinates are not afraid of losing their jobs and have time to help others (Csepregi, 2012a). Bureaucratized sharing process may not always require the imposition of increased administrative controls, rules and regulations instead one can remain in direct control of the knowledge resources, and also decide what is needed and what is not needed to be shared (Brivot, 2011). Because of the bureaucratic features and working in the same area, there is time when needed to share knowledge which is the key to success. In organizations producing products the different work areas are more separated and here middle managers and their subordinates often meet and/or work together which facilitates their availability (Csepregi, 2012a). In case of problem occurring in their area and/or affecting production subordinates, because of their interest, are also fostered to be available and to find solution to the problem. For this the competence of problem solving is needed that covers the ability to work with others in order to identify and implement solutions to problems (Matook and Maruping, 2014).

While middle managers primarily working at national and privately owned organizations and secondly working at organizations providing mostly and only services are less available for their subordinates and vice versa (Gaál et al., 2013). The fierce competition existing at these organizations also determines the middle manager-subordinate relationships. Furthermore, middle managers assuming their subordinates know what they need to know and can accomplish their work without their help results in a gap between them. Especially in organizations providing services, damage occurs when individual features dominate and the middle manager and subordinates are not motivated to work together, thus being less available (Csepregi, 2012a). However, perceived manager support and their encouragement to share knowledge can enhance knowledge sharing and its usefulness (Cabrera et al., 2006; Kulkarni et al., 2006).

T3.3: There are differences in the usefulness of knowledge among middle managers by the customer claims fulfilled by their organization.

Thus middle managers working at organizations fulfilling often changing and complex customer claims are considered more useful for other middle managers and vice versa. In these organizations communication is indispensable. Therefore communicating and sharing necessary knowledge plays an important role in fulfilling the required claims (Csepregi, 2012a). Furthermore, often changing customer claims require up-to-date middle managers as well. This can be achieved by understanding how consumers indirectly and/or directly interact, communicate and competently manage these interactions and communicate in order to maximize satisfaction among customers (Ekpo et al., 2014).

Whilst middle managers working at organizations fulfilling not changing and fix customer claims are less useful for other middle managers and vice versa. Interviews showed that in these organizations middle managers accept and are accustomed to rules and solutions that have to be applied and are rarely subject to change. Paroutis and Saleh (2011) revealed that there is a relationship between knowledge sharing and old habits of doing things. Middle manager also have old habits concerning their work, often conduct routine work, and are not open to solutions changing their routines, thus finding others ideas and knowledge not seems to be useful and important (Csepregi, 2012a).

T3.4: There are no differences in the usefulness of knowledge among the middle managers and their subordinates on the basis of organizational characteristics.

Since no class could be revealed by decision tree it was not possible to conduct any further analysis. This means that no significant differences could be revealed based on the investigated organizational characteristics concerning the middle manager-subordinate usefulness of knowledge.

This study revealed that the knowledge sharingmaturity of middle managers working at medium- and large-sized enterprises in Hungary is measured by four elements. Differences were found in three knowledge sharing maturity elements on the basis of two of the investigated individual characteristics. The influencing individual characteristics were functional area, active working years or age. In the remaining one case (middle manager-middle manager usefulness of knowledge) the effect of only one influencing factor (length of working years) resulted in difference. Furthermore differences were found in two knowledge sharing maturity elements on the basis of two of the investigated organizational characteristics. The influencing factors were the type and the activity of the organization. Concerning the other two knowledge sharing maturity elements, in one case (middle manager-middle manager usefulness of knowledge) only one influencing factor (customer claims fulfilled by the organization) resulted in differences, and regarding the other (middle manager-subordinate usefulness of knowledge) no differences could be revealed based on the influencing factors.

\section{PRACTICAL IMPLICATION AND FUTURE PLANS}

The results of this study could help not only middle managers but top managers and other employees as well. Their knowledge sharing maturity can be measured and developed. Moreover, individual and organizational characteristics affecting knowledge sharing maturity could also be determined.

As a continuation of this study the following options could be considered: by repeating the survey among middle managers, changes in their knowledge sharing maturity and regarding individual and organizational characteristics could be revealed; by investigating managers/ employees from other organizational levels, their knowledge sharing maturity could also be revealed, and their results could be compared with the recent results; by extending the study to other countries the Hungarian results could be compared with other countries' results considering the national cultural differences as well. 


\section{REFERENCES}

[1] Alavi, M. Kayworth, T.R. and Leidner, D. E. 2005. An empirical examination of the influence of organizational culture on knowledge management practices., Journal of Management Information Systems. 22(3), 191-224.

[2] Amayah, A. T. 2013. Determinants of knowledge sharing in a public sector organization. Journal of Knowledge Management. 17(3), 454-471.

[3] Assudani, R .H. 2005.Catching the chameleon: Understanding the elusive term 'knowledge'. Journal of Knowledge Management. 9(2),31-44.

[4] Bakacsi, Gy. Takács, S. Karácsonyi, A. and Imrek, V. 2002. Eastern European Cluster: Tradition and transition. Journal of World Business. 37(1), 69-80.

[5] Balogh, A. Gaál, Z. and Szabó, L. 2011. Relationship between organizational culture and cultural intelligence. Management \& Marketing. 6(1), 95-110.

[6] Barnes, J. Bessant, J. Dunne, N. and Morris, M. 2001. Developing manufacturing competitiveness within South African industry: The role of middle management. Technovation. 21(5),293-309.

[7] Berry, G.R. 2011. A cross-disciplinary literature review: examining trust on virtual teams. Performance Improvement Quarterly,.24(3), 9-28.

[8] Berry, J.W. Kim, U. Minde, T. and Mok, D. 1987. Comparative studies of acculturative stress. International Migration Review. 21(3,Special Issue: Migration and Health), 491-511.

[9] Bhatt, G. D. 2002. Management strategies for individual knowledge and organizational knowledge. Journal of Knowledge Management. 6(1), 31-39.

[10] Bogdány E. and Costa, J.P. 2013. The relationship between organizational culture and the transfer of management functions and roles in the SMEs succession: a case studies between Hungary and north of Portugal. Tourism \& Management Studies. 9(1), 121-128.

[11] Bognár, F. 2014. The impact of organizational culture and maintenance strategies in organizational business processes. Pannon Management Review. 38(1),93-127.

[12] Boh, W.F.and Wong, S.S. 2013. Organizational climate and perceived manager effectiveness: influencing perceived usefulness of knowledge sharing mechanisms. Journal of the Association for Information Systems. 14(3), $122-152$.

[13] Brachos, D. Kostopoulos, K. Soderquist, K. E. and Prastacos, G. 2007. Knowledge effectiveness, social context and innovation.Journal of Knowledge Management. 11(5), 31-44.

[14] Brivot, M. 2011. Controls of knowledge production, sharing and use in bureaucratized professional service firms. Organization Studies. 32(4), 489-508.

[15] Buehner, M. Kroener, S. and Ziegler, M. 2008. Working memory, visual-spatial intelligence and their relationship to problem-solving. Intelligence.36(4), 672-680.

[16] Cabrera, A. Collins, W.C. and Salgado, J. F. 2006. Determinants of individual engagement in knowledge sharing. International Journal of Human Resource Management. 17(2), 245-264.

[17] Chandler, A. D. 1977. The Visible Hand: The managerial revolution in American business. Harvard University Press, Cambridge, MA.

[18] Cheng, J.H. Yeh, C.H. and Tu, C. W. 2008. Trust and knowledge sharing in green supply chains. Supply Chain Management. 13(4), 283-295.

[19] Chow, W.S. and Chan, L. S. 2008. Social network, social trust and shared goals in organizational knowledge sharing. Information \& Management. 45(7), 458-465.

[20] Connelly, C.E. and Kelloway, E. K. 2003.Predictors of employees' perceptions of knowledge sharing cultures. Leadership \& Organization Development Journal. 24(5/6), 294-301.

[21] Conway, E. and Monks, K. 2011.Change from below: the role of middle managers in mediating paradoxical change. Human Resource Management Journal. 21(2), 190-203.

[22] Christensen, P. H. 2007. Knowledge Sharing: Moving away from the obsession with best practices. Journal of Knowledge Management. 11(1), 36-47.

[23] Crouch, A, Yetton, P. 1988.Manager-subordinate dyads: Relationships among task and social contact, manager friendliness and subordinate performance in management Groups. Organizational Behavior \& Human Decision Processes. 41(1), 65-82.

[24] Csepregi, A. 2012a. Middle managers' knowledge sharing and their competences. LAP Lambert Academic Publishing, Saarbruecken.

[25] Csepregi, A. 2012b, Lost in knowledge sharing: Possible lessons and implications for middle managers and their organizations. Pannon Management Review. 1(1), 67-88.

[26] Davenport, T. H. and Prusak, L. 1998. Working Knowledge, Harvard Business School Press, Boston, MA.

[27] De Vries, R.E. van den Hooff, B. and de Ridder, J. A. 2006. Explaining knowledge sharing: The role of team communication styles, job satisfaction, and performance beliefs. Communication Research. 33(2), 115-135. 
[28] DeLong, D. W. and Fahey, L. 2000. Diagnosing cultural barriers to knowledge management.Academy of Management Executive. 14(4, November), 113-127.

[29] Dunford, R. 2000. Key challenges in the search for the effective management of knowledge in management consulting firms. Journal of Knowledge Management. 4(4), 295-302.

[30] Dutton, J.E. Ashford, S.J. O’Neill, R.M. Hayes, E. and Wierba, E. E. 1997.Reading the wind: How middle managers assess the context for selling issues to top managers. Strategic Management Journal. 18(5), 407-425.

[31] Eaves, S. 2014. Middle management knowledge by possession and position: A panoptic examination of individual knowledge sharing influences. The Electronic Journal of Knowledge Management. 12(1), 71-88. available at: www.ejkm.com (accessed 2 September 2014)

[32] Ekpo, A.E. Riley, B.K. Thomas, K.D. Yvaire, Z. Gerri, G.R.H. and Muñoz, I. I. 2014. As worlds collide: The role of marketing management in customer-to-customer interactions. Journal of Business Research, in press.

[33] Gaál, Z. Szabó, L. and Csepregi, A. 2013, Organizational characteristics that influence the way middle managers and their subordinates are available to each other. in Proceedings of the 14th European Conference on Knowledge Management, Vol.1, in Kaunas, Lithuania. Academic Conferences and Publishing, Reading, 227-235

[34] Gaál, Z. Szabó, L. Obermayer-Kovács, N. Kovács, Z. Csepregi, A. 2011. Knowledge Management Profile: An innovative approach to map knowledge management practice, in Eardley, A. Uden, L. (Eds.) Innovative Knowledge Management: Concepts for Organizational Creativity and Collaborative Design. IGI Global, Hershey, PA, 253-263.

[35] Gaál, Z. Szabó, L. Obermayer-Kovács, N. and Csepregi, A. 2012a. Middle managers' maturity of knowledge sharing: Investigation of middle managers working at medium- and large-sized enterprises. The Electronic Journal of Knowledge Management. 10(1), 26-38.

[36] Gaál, Z. Szabó, L. Obermayer-Kovács, N. and Csepregi, A. 2012b. Are there differences in the way middle managers and their subordinates are available for each other based on the middle Managers individual characteristics?" in Proceedings of the 13th European Conference on Knowledge Management, Vol.1, in Cartagena, Spain. Academic Publishing, Reading, 370-380.

[37] Glasø, L. and Einarsen, S. 2006. Experienced affects in leader-subordinate relationships. Scandinavian Journal of Management, 22(1), 49-73.

[38] Gupta, A. K. and Govindarajan, V. 2000. Knowledge management's social dimension: Lessons from Nucor Steel. Sloan Management Review, 42(1), 71-80

[39] Ireland, R. 1992. Corporate culture is best conveyed by mid-level managers. Baylor Business Review.10(1), 18-19.

[40] Jiacheng, W., Lu, L. and Francesco, C. A. 2010. A Cognitive model of intra-organizational knowledge-sharing: Motivations in the view of cross-culture. International Journal of Information Management, 30(3), 220-230.

[41] Heidrich, B. and Alt, M.A. 2009. Godfather management? The role of leaders in changing organizational culture in transition economies: A Hungarian-Romanian comparison. Management, 4(4), 309-327.

[42] Heidrich, B. and Chandler, N. 2011. The effect of market-oriented subcultures on post-merger higher education institutions. US-China Education Review. 5, 666-681.

[43] Hermanrud, I. 2012. The transfer of knowledge and the problems of identity in a managed and online context. Nordic Journal of Social Research. 3, 52-70.

[44] Hinds, P. J. and Pfeffer, J. 2003. Why organizations "don't know what they know", in Ackerman, M. Pipek V. and Wulf V. (Eds.), Beyond Knowledge Management: Sharing Expertise, MIT Press, Cambridge, MA, 3-26.

[45] Ho, L.A., Kuo, T. H. Lin, C. and Lin, B. 2010. The mediate effect of trust on organizational online knowledge sharing: An empirical study. International Journal of Information Technology \& Decision Making. 9(4), 625-644.

[46] Holste, J. S. and Fields, D. 2010.Trust and Tacit Knowledge Sharing and Use. Journal of Knowledge Management. $14(1), 128-140$.

[47] Kaplan, R. E. 1984. Trade routes: The manager's network of relationships. Organizational Dynamics. 12(4), 37-52.

[48] Klimko, G. 2001. Knowledge management and maturity models: Building Common Understanding, in Proceedings of 2nd European Conference on Knowledge Management, in Bled, Slovenia, 2007, MCIL, Reading, 269-278.

[49] KPMG Hungary 2000. Knowledge Management in Hungary: Research, KPMG Consulting Report, Budapest

[50] Kulkarni, U.R. Ravindran, S. and Freeze, R. 2006. A knowledge management success model: Theoretical development and empirical validation. Journal of Management Information Systems. 23(3), 309-347.

[51] Lambe, P. 2014. Organising Knowledge: Taxonomies, Knowledge and Organisational Effectiveness, Elsevier Science, Burlington, MA.

[52] Li, W. 2010. Virtual knowledge sharing in a cross-cultural Context.Journal of Knowledge Management. 14(1), 38-50.

[53] Lin, H. F. 2007a. Effects of extrinsic and intrinsic motivation on employee knowledge sharing intentions. Journal of Information Science. 33(2), 135-149.

[54] Lin, H.F. 2007b. Knowledge sharing and firm innovation capability: An empirical study. International Journal of Manpower. 28(3/4), 315-332. 
[55] Magnier-Watanabe, R. and Senno, D. 2010. Shaping knowledge management: Organization and national culture.Journal of Knowledge Management. 14(2), 214-227.

[56] Mantere, S. 2008. Role expectations and middle manager strategic agency. Journal of Management Studies. 45(2),294-316

[57] Matook, S. and Maruping, L. M. 2014. A competency model for customer representatives in agile software development projects. MIS Quarterly Executive.13(2),77-95.

[58] Matzler, K. Renzl, B. Müller, J. Herting, S. and Mooradian, T.A. 2008. Personality traits and knowledge sharing. Journal of Economic Psychology. 29(3), 301-313.

[59] McAdam, R., Moffett, S. and Peng, J. 2012. Knowledge sharing in Chinese service organizations: a multi case cultural perspective. Journal of Knowledge Management. 16(1), 129- 147.

[60] Mehra, A. Dixon, A.L. Brass, D. J. and Robertson, B. 2006. The social network ties of group leaders: Implications for group performance and leader reputation. Organization Science, 17(1), 64-79.

[61] Menon, A. and Varadarajan, P. R. 1992. A model of marketing knowledge use within firms. Journal of Marketing. 56, 53-71.

[62] Moeller, K and Svahn, S. 2004. Crossing East-West boundaries: Knowledge sharing in Intercultural business networks. Industrial Marketing Management. 33(3), 219-228.

[63] Mueller, J. 2012. Knowledge sharing between project teams and its cultural antecedents. Journal of Knowledge Management. 16(3), 435-447

[64] Myatt, G.J. and Johnson, W. P. 2009. Making sense of data II, Wiley-Blackwell. Hoboken, NJ.

[65] Nahavandi, A. and Malekzadeh, A. R. 1988. Acculturation in mergers and acquisitions. Academy of Management Review, 13(1), 79-90.

[66] Nahavandi, A. and Malekzadeh, A. R. 1993. Organizational culture in the management of mergers. Quorum Books, Westport, CT.

[67] Nonaka, I. 1988. Towards middle up/down management: Accelerating information creation. Sloan Management Review. 29(3), 9-18.

[68] Novick, L. R. and Bassok, M. 2005. Problem solving, in Holyoak, K.J. and Morrison R.G. (Eds.), The Cambridge handbook of thinking and reasoning, University Press, Cambridge, NY, 321-349.

[69] Obermayer-Kovács N. and Komlósi E. 2014. What emotional intelligent traits enable managers to share knowledge for work-related quality of life? In Proceedings of Makelearn 2014:Human Capital without Borders International Conference. Portorož, Slovenia. 325-333

[70] Østerlund, C. and Carlile, P. 2005. Relations in Practice: Sorting Through Practice Theories on Knowledge Sharing in Complex Organizations. The Information Society. 21(2), 91-107.

[71] Pappas, J.M. Flaherty, K. E. and Wooldridge, B. 2003. Achieving strategic consensus in the hospital setting: A middle management perspective. Hospital Topics, 81(1),15-22.

[72] Paroutis, S. and Saleh, A. A. 2011. Determinants of knowledge sharing using Web 2.0 technologies.Journal of Knowledge Management. 13(4), 52-63.

[73] Pasher, E. and Ronen, T. 2011. The Complete Guide to Knowledge Management, Wiley, Hoboken, NJ.

[74] Paulk, M.C. Weber, C.V. Curtis, B. and Chrissis, M. B. 1994. The Capability Maturity Model: Guidelines for Improving the Software Process, Addison-Wesley, Reading, MA.

[75] Paulzen, O., Doumi, M. Perc, P. and Cereijo-Roibas, A. 2002. A maturity model for quality improvement in knowledge Management, Enabling Organisations and Society through Information Systems, in ACIS 2002 Proceedings, Paper 5, in Melbourne, Australia, 2002, available at: http://aisel.aisnet.org/acis2002/5/, (accessed 8 December 2010)

[76] Politis, J.D. 2003. The connection between trust and knowledge management: what are its implications for team performance. Journal of Knowledge Management. 7(5), 55-66.

[77] Powell, W.W Koput, K. W. and Smith-Doerr, L. 1996. Interorganizational collaboration and the locus of innovation: networks of learning in biotechnology. Administrative Science Quarterly. 41, 116-45.

[78] Pullig, C. James, I. Maxham, G. Joseph, J. and Hair, F. 2002. Salesforce automation systems: An exploratory examination of organizational factors associated with effective implementation and salesforce productivity. Journal of Business Research. 55(5), 401-415.

[79] Renzl, B. 2008. Trust in management and knowledge sharing: The mediating effects of fear and knowledge documentation. Omega. 36,206-220.

[80] Reychav, I. and Weisberg, J. 2010. Bridging Intention and Behavior of Knowledge Sharing. Journal of Knowledge Management. 14(2), 285-300.

[81] Rosendaal, B. 2009. Sharing knowledge, being different and working as a team. Knowledge Management Research \& Practice, 7(1), 4-14

[82] Sayles, L. R. 1993. Doing things right: A new imperative for middle managers. Organizational Dynamics. 21(4), 5-14. 
[83] Schlesinger, L. A. and Oshry, B. 1984. Quality of work life and the manager: Muddle in the middle. Organizational Dynamics. 13(1), 5-19.

[84] Seba, I. Rowley, J. and Delbridge, R. 2012. Knowledge sharing in the Dubai police force. Journal of Knowledge Management. 16(1), 114-128.

[85] Shariq, S.Z. and Vendelo, M. T. 2008. Tacit knowledge sharing, in Jennex, M. (ed.), Knowledge Management: Concepts, Methodologies, Tools, and Applications, IGI Global, Hershey, PA, 3022-3030.

[86] Sondergaard, S. Kerr, M. and Clegg, C. 2007. Sharing knowledge: Contextualising socio-technical thinking and practice. The Learning Organization. 14(5), 423-435.

[87] Staehle, W. and Schirmer, F. 1992. Lower-level and middle-level managers as the recipients and actors of human resource management, International Studies of Management and Organization, 22(1), 67-89.

[88] Suppiah, V. and Sandhu, M. S. 2011. Organisational culture's influence on tacit knowledge-sharing behavior. Journal of Knowledge Management. 15(3), 462-477.

[89] Sussman, S.W. and Siegal, W. S. 2003. Informational influence in organizations: An integrated approach to knowledge adoption. Information Systems Research,14(1), 47-65.

[90] Swift, M. Balkin, D.B. and Matusik, S. F. 2010. Goal orientations and the motivation to share knowledge. Journal of Knowledge Management. 14(3), 378-393.

[91] Tan, H. H. and Zhao, B. 2003. Individual- and perceived contextual-level antecedents of individual technical information inquiry in organizations. Journal of Psychology, 137(6), 597-621.

[92] Uyterhoeven, H. 1989. General managers in the middle. Harvard Business Review. 67(5),136-145.

[93] Vuori, V. and Okkonen, J. 2012. Knowledge sharing motivational factors of using an intra-organizational social media platform. Journal of Knowledge Management. 16(4), 592-603.

[94] Walter, C. and Ribiere, V. 2013. A citation and co-citation analysis of 10 years of KM theory and practices. Knowledge Management Research \& Practice. 11(3), 221-229

[95] Wang, S. and Noe, R.A. 2010. Knowledge sharing: A review and directions for future research. Human Resource Management Review, 20(2), 115-131.

[96] Witherspoon, C.L. Bergner, J. Cockrell, C. and Stone, D. N. 2013. Antecedents of organizational knowledge sharing: a meta-analysis and critique. Journal of Knowledge Management, 17(2), 250-277.

[97] Xin, K.R. and Pelled, L. H. 2003. Supervisor-subordinate conflict and perceptions of leadership behavior: A field study. The Leadership Quarterly. 14(1),25-40.

[98] Yang, T.M. and Maxwell, T. A. 2012. Information-sharing in public organizations: a literature review of interpersonal, intra-organizational and inter-organizational success factors. Government Information Quarterly. 28, $164-175$.

[99] Zboralski, K. 2009. Antecedents of knowledge sharing in communities of practice.Journal of Knowledge Management. 13(3),90-101.

\section{Author' biography with Photo}

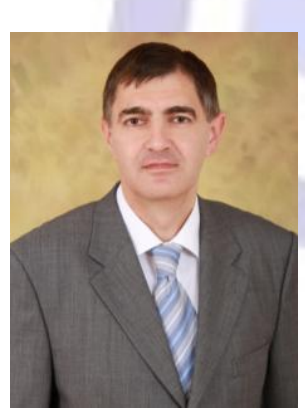

Lajos Szabó is an Associate Professor, Head of the Department of Management at the University of Pannonia. He was educated at the University of Veszprém and at the Eni Scuola Superiore Enrico Mattei in Italy. He received his PhD in Strategic Management. He is founder member of the Hungarian Project Management Association, and the co-director of the Strategic Research Group at the University of Pannonia. He has published numerous articles and presented his work at national and international conferences. His main fields of interest include intercultural, project and knowledge management.

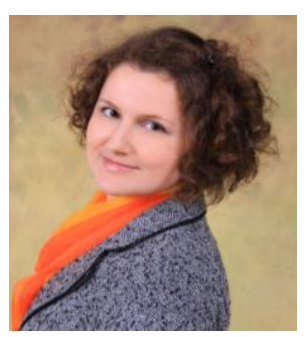

Anikó Csepregi is an Assistant Professor at the Department of Management, Faculty of Business and Economics, at the University of Pannonia in Veszprém. Her research interests are competence, knowledge and project management. She has presented several papers at conferences in Hungary and abroad, and she has authored and co-authored several articles in these areas. She is an editorial board member of knowledge management journals and a committee member of international knowledge management conferences. 